\title{
AUDIENCE PERSPECTIVE ON TODD PHILLIPS'S JOKER (2019): A LACANIAN PSYCHOANALYSIS
}

\author{
Alifiadita Nindyarini Wirawan \\ e-mail: alifiaditanindy9729@gmail.com
}

\begin{abstract}
The occurrence of American movies which raise psychological issues as part of the main theme often triggers audiences in producing various interpretations. In this respect, the writer chose one of the most popular American movies entitled Joker (2019), directed by Todd Phillips. The movie highlights not only social issues but also psychological issues that engage audiences to produce diverse interpretations, including misinterpretations toward the stereotype of people who suffer mental illness. Therefore, the writer aims to analyze further how the audience perceives and evaluates Joker (2019). Data collected through audiences' statements in IMDb as an online database of information of films and critical reviews. Psychoanalysis Lacanian: the real, the imaginary, and the symbolic, is applied to comprehending the American audiences response and their interpretations towards Joker (2019) movie. The result of study reveals that audiences' diverse life experience and background is actually giving major influence towards their interest, response, and interpretations to Joker (2019) movie.
\end{abstract}

Keywords: Audience analysis; Jacques Lacan's Psychoanalysis;

Joker; psychological issues

DOI $\quad$ : https://doi.org/10.22146/rubikon.v8i1.65484

Available at https://jurnal.ugm.ac.id/rubikon/article/view/65484

This work is licensed under a Creative Commons Attribution-ShareAlike 4.0 International License

\section{INTRODUCTION}

The interesting part of a movie is allowing the audience to witness the variety of social and cultural phenomena happening in society, including psychological issues. Greenstein (2017) explained that it is becoming increasingly more common for Hollywood to highlight mental health conditions in films. The reason is that mental illness affects
Article information

Received: 28 January 2021

Revised: 11 February 2021

Accepted:25 February 2021 millions of Americans; it is an extremely relatable theme. Thus, it is unsurprising to find the creation of American movies often focused on creating characters who suffer psychological disorders or mental illness. By comprehending the condition of the main character, the audience could perceive the portrayal of an individual's life experience in dealing with diverse psychological issues. 
In this respect, the writer chose Joker (2019) movie directed by Todd Phillips, as one of the most popular American movies that contained social and psychological issues, which puts the emphasis on psychological phenomenon through the main character's characterization. Furthermore, the emergence of Joker (2019) movie is highly attracting many audiences, particularly American society, who could relate the story with their own life experience, which triggers them to acknowledge and interpret mental health issues portrayed within the movie. Travis Langley (2019) states, in his book The Joker Psychology: Evil Clowns and the Women Who Love Them, that one of the particular aspects which attract American society to watch the movie is because it is so easy for the audience to project anything onto that adaptable character (p. 27). Henceforth, it seems like the audience has particular diverse perspectives in perceiving the movie, especially in interpreting the story. Thus, it is quite common to find various interpretations produced by audiences, including misinterpretation of the mental illness, which often becomes associated with violence. In this respect, Ken Severson as a writer of an article entitled "Is 'Joker' Dangerous? The Joker Movie Controversy Explained," clarified that despite many thematically disturbing elements, the movie itself did not inspire violence, but it is quite the opposite where actually the director Todd Phillips and Scott Silver as the writer trying to convey a message and a depiction of how the setting, the story, and the character within the movie depict a symbol of political violence, injustice, and discrimination overpower domination by the rich people in Gotham city where it is truly happening in today's context of the society in America. Therefore, the analysis of the audience's misinterpretation is truly significant because it requires further investigation in acknowledging why and how the text or the movie could direct the audience's consciousness in producing diverse interpretations based on their understanding. According to Vodicka (in Striedter's, 2013: 121) stated that "we always keep in mind not only its existence but also its reception: we must take into account how it is esthetically perceived, interpreted, and evaluated by the reading public. Only if read does the work achieve its esthetic realization, only in this way does it become an esthetic object in the reader's consciousness". In this respect, in order to comprehend the reader's consciousness in producing diverse interpretations after perceiving the movie or the text, it acquires a theory that is capable of explaining the reader's psychological stages. By implementing the concept of Lacanian psychoanalysis, it can help the process of comprehending the readers' psychological stages, which is concerning their production of diverse interpretations, including their misunderstanding of mental illness within the movie.

Furthermore, in order to reveal how the audience perceives Joker (2019) movie and how the movie could affect them in creating a particular interpretation, the writer needs to acquire a proper way of elaborating the main discussion through applying suitable perspective and approach. Thus, this paper is a form of impact/effect study to see how such interrelationship between the audience and the movie is capable of producing the influences toward each other by comprehending the audience interest toward the movie and how the audience produce diverse interpretations could create such a popular image over the creation of Joker (2019) movie as part of American popular culture. In this respect, the 
writer chooses to perform Cawelti's impact/effect study because it is intended to perceive how the creation of Joker (2019) is able to direct the audience to produce various interpretations and how the audience's construction of various interpretations, argument, and discussion affects the popularity of the movie itself. The implication of psychoanalysis by Jacques Lacan is also chosen by the writer as an approach to perceive and understand further related to why American audiences seem to be so interested in Joker (2019) movie until it could influence them to produce or construct diverse interpretations.

Moreover, in order to construct relevant arguments, it is very necessary to involve the audience's perspective to perceive and process Joker (2019) movie as an object of analysis which sees the audience as an important role in producing interpretation and giving influence over the movie itself. Therefore, quotations from IMDb, which is basically an online database of information related to films, television programs, home videos, video games, and streaming content online including cast, production crew, and personal biographies, plot summaries, trivia, ratings, and fan, and critical reviews are selected as the primary data of this research. Indeed, to support the argument, the writer applied library research to obtain the acquired data for the paper. According to George (2008, 6), "library research involves identifying and locating sources that provide factual information, personal or expert opinion on a research question; a necessary component of every other research method at some point." Briefly, in the following discussion, the writer is focusing on revealing the facts regarding the reason the audience can show significant interest in the movie and how the movie is seen by the audience from various perspectives by considering their distinguished circumstances or comprehension toward the story of the movie itself. In order to accomplish the main objective of the paper, the further explanation is elaborated through three stages of Lacan's psychoanalysis which are, The Real, The Imaginary, and The Symbolic.

\section{DISCUSSION}

The emergence of Joker (2019) movie within society across the globe, especially in the United States of America, affects many audiences in diverse ways. It could be seen through how significant is the construction and production of interpretations by American society in perceiving Joker (2019) movie from its released date until now. Based on Wilkinson's survey of the audience's response over the premiere of Joker (2019) movie, 64 percent of American society seemed mostly interested in contextually correlating the movie based on their convention, particularly in discussing mental health issues depicted within the movie. Accordingly, there must be a relevant explanation to explain why American audiences show significant interest in the Joker (2019) movie and capable of engaging them in producing or constructing diverse interpretations of the movie itself. Surely, psychoanalytic explanations could relate and elaborate the condition of American society as part of the audience in producing interpretations.

Based on Jacques Lacan regarding his thought of psychoanalysis is basically about how the development of a human's psychological state is explained into three stages which are, The Real, The Imaginary, and The Symbolic. By perceiving how 
American society eventually likes to watch Joker (2019) movie and produce their own interpretations could be understood by correlating their psychological state through elaborating it into three stages of psychoanalysis by Jacques Lacan.

\section{The First Stage of Lacan's Psychoanalysis: The Real}

Basically, the real is explained by Lacan as a primary stage or the natural state of an individual who is going through a phase of fullness or completeness where it focuses only on fulfilling the "needs" of humans. Within this phase, the individual is still unable to recognize themselves as a specific individual with their own identity, and hard to feel loss, emptiness, or lack ness during this stage since there is no clear language constructed into their mind. Thus, within this stage, an individual only considers their fulfillment of basic "needs" and is not quite attentive in acknowledging or recognizing everything that happens around them. Their focus only ensures that they will always feel fulfilled and complete physically as a human beings. Accordingly, it is relevant to perceive how American society is also ever going through the stage of only concerning on fulfillment and completeness as natural as it is, even though they are known as an individualistic citizen but their sense of need to be fulfilled is actually a natural phenomenon or process based on Lacan's thought. Moreover, it also makes them experience the phase of eagerness. An individual only wants to do anything that regards their fulfillment, just like in the case of why American society wants to watch Joker (2019) movie because it is part of basic fulfillment, particularly a need for entertainment. The following quotation will prove how the audiences of Joker (2019) movie got difficulty coping with the essence of the story but remain capable of enjoying it as an interesting entertainment.

Do not really understand all the tens here. Sure, a good movie, good acting, nice shooting. But the plot is not so intriguing. At times it is really long and somewhat boring. I needed to double-check the genre to see if this is a drama or what. Crime, drama, thriller it said. I would put it maybe $90 \%$ in the drama and rest in thriller (Harkap, 9 January 2020).

Based on the statement, it could be perceived how the audience seems to be getting difficulty comprehending the story deeply because when they watch Joker (2019) movie, they are not directly aware of what is actually being delivered within the movie, but they remain to enjoy it as entertainment. They are only capable of producing surface or spontaneous interpretation. Thus, the moment when the audience perceives Joker (2019), they are hardly capable of producing any coherent interpretations since not all of the audiences could directly understand the implicit messages delivered within the movie, which raises the theme of psychological issues. It is because based on Harvard Medical School Affiliate's article related to barriers of mental health among the American community is showing the fact that Americans' awareness toward the urgency of giving more space for mental health discussions openly among the community is quite low. Although, the truth exposes many of the society is actually going through a diverse psychological issue or suffers mental illness unnoticed by the majority of Americans.

Therefore, within this stage of Real, the audience is only capable of fulfilling their needs of entertainment through watching Joker (2019) movie. The main reason why several 
audiences, like the previous example unable to acknowledge "the sense of lack ness" in interpreting the movie is because they merely make the interpretations based on their basic or common insight related to mental illness without having further knowledge about the issue. Moreover, the following statement also proves how the audience could misinterpret the movie because they only can enjoy the movie as entertainment and are considered unnecessarily to be understood deeply. Indeed, it makes the movie seem to finish so early because they are incapable of sensing the atmosphere and excitement transferred from the movie.

While I enjoyed the film, it felt pretty short. When "The End" appeared on the screen I couldn't help but think - "That's it?"

Joaquin Phoenix was fantastic with his new take on the Joker, and it's mesmerizing to see his facial expressions keep changing. And his Joker laugh is unique - sinister and full of Joker's madness (Danteshamest, 3 October 2019).

Through perceiving the statement above, it could be inferred to how within the stage of 'real' an individual still only concerns about completing the needs. In this case, it is represented by the audience of Joker (2019), who merely concentrates on the need to be entertained by watching the movie. Furthermore, based on the audience's statement above, there is a crucial aspect that needs to be taken into consideration in understanding why Americans unable to interpret Joker (2019) movie coherently. They seem to be only capable of enjoying the cinematic features of good performance from the movie or merely feel satisfied with the performance of the actor/actress. One of the main aspects is because, within this stage, they do not possess enough language or awareness toward mental health issues.

Apparently, not every American is quite knowledgeable and well informed about the discussion of psychological issues, often among their community. Surely, it makes people who do not have the experience or exposure to this kind of issue will possibly find it challenging to be aware of the important messages within the story and what is actually the grand purpose by watching Joker (2019) movie toward the audience's life. So, for the audience who only consider Joker (2019) movie as an interesting entertainment is truly missing the whole idea, since they are incapable of sensing the atmosphere of solid energy within the story where it lays a strong reminder for everyone, especially the audience to keep their sense of humanity and morality within their lives. The following statement from the audience of Joker (2019) is giving an example of how the audience seems to be difficult to comprehend regarding how the occurrence of the movie itself could create such a sensation toward the movie industry and the reason many people put such high appreciation over the movie itself.

I thought this film was good but I just don't get the hype personally. The acting was amazing and the film was good overall but I think 'masterpiece' and 'film of the year' are a bit overused throughout the reviews. In no way did I dislike this film, I thought it was really good, just overhyped. I feel as though a lot of the $10 / 10$ reviews are purely based on the fact that it already has amazing reviews and so people want to carry the praise further and that it is about the Joker (Romanwatson, 6 October 2019).

Based on the statement above, the audience is actually enjoying the movie and feels satisfied too over the movie with the 
performance of the acting as well as other elements within the movie, which signalized that the movie is evaluated as an attractive entertainment. However, the audience still wonders why the occurrence of Joker (2019) movie is overhyped by other audiences and considers the labeling of the movie as a 'masterpiece' is too much. Basically, this kind of thought could occur among the audience because those who are not quite familiar with or feel related to the movie will perceive the movie from a different perspective. They will only evaluate the movie from the cinematic elements and focus on whether the actors could perform their roles goodly or badly. Henceforth, their distinct concern makes them incapable of producing similar hype with other audiences that have a different focus, particularly in acknowledging the implicit values conveyed within the movie, which is considered as something relatable toward their life experience or their circumstances. On the bottom line, regardless of the audience differences regarding their perspective in evaluating the movie, they are still an audience who perceive the movie as a fulfillment of their need over entertainment. In this case, Joker (2019) movie is mostly considered successful enough for most of the audience in entertaining them.

\section{The Second Stage of Lacan's Psychoanalysis: The Imaginary}

Furthermore, based on Lacan regarded to the imaginary stage is where it called a "mirror stage" when an individual started to acknowledge his existence and identify his "I" or self-knowledge through his reflection in the "mirror" that means the interpretation of selfidentity is based on the self-imaginary form where its originality of identification is very doubtful because the "mirror" reflecting distorted image. It makes unreliable identification of self-hood. In this case, by perceiving how the audience is capable of producing a variety of interpretations toward the emergence of Joker (2019) movie could be understood that the audience only interprets the movie based on what they see within the movie literally without having supporting insight which supposed to help them to comprehend the movie deeply. Henceforth, for the audience who produce misinterpretation over mental health issues carried out by the main character's behaviors that often perform violence in several scenes makes them construct their own perspective related to how mental illness is always associated with violence.

Conversely, not every category of mental illness is associated with people who tend to commit violence because it requires deeper understanding related to every characteristic and symptom of diverse mental illness to enable us in identifying someone who possibly suffers any particular mental illness. This is the stage where the audience is in the imaginary stage when they attempt to interpret Joker (2019) movie as a phenomenon of an individual who faces a psychological issue that finds pleasure in committing violence into their basis or personal insight in identifying people who suffer mental illness in reality context. So, when they see the movie, it affects them in the most constructive form of evaluating mental health issues. Even though their interpretations are unable to be accountable fully and probably still considered as "imaginary" perception, but at least that is what they perceived from the movie. Thus, based on the Guardian Weekly article written by Anna Driscoll and Mina Husain on October $21^{\text {st }}, 2019$, explained that portrayals of mental 
illness in the film could perpetuate unfounded stereotypes and spread misinformation.

Clearly, the situation of the audience performs misinterpretation too toward the movie, proven by the research done by Damian from the University of Otago in Reynold's article about how films like 'Joker' could shape attitudes towards mental illness. The results of the research concluded that watching the film did increase negative perceptions of mental illness where the participants start to receive several thoughts in the form of stereotypes over people who suffer a mental illness which tends to perform misperception toward these people. This kind of misperception produced by the audience seems to be influenced by the situation of America as well, where people possess negative stigma over mental illness. According to Parcesepe and Cabassa (2013) stated that the existence of public stigma becomes a pervasive barrier that caused many individuals in the U.S. to receive negative treatment from the public and afraid of having mental health care, where this kind of stigma is associated with a lack of engagement in mental health care and worse treatment outcomes. Therefore, it explained the phenomenon of misinterpretation toward the movie because not only the audience is relying on their own convention in interpreting the movie but also the influence of public stigma toward mental illness. It led them to construct unclear or unreliable interpretations where it happens during the imaginary stage. In addition, this stage is also explained why such diversity of interpretations could occur because there is a "demand" that expects them to be more engaged and active in producing diverse interpretations. In the following statement, it is about one of the audience's perspective toward Joker (2019) movie that apparently shows the audience's incapability to discover the true point of the movie and comprehend the whole idea of the story including the character coherently.

I was expecting a masterpiece and oscar worthy film from all the hype. I actually didn't enjoy watching this movie. There was no message, it was slow and the Joker turned out just to be the son of a schizophrenic and went crazy over a slight amount of bullying. I don't see how anyone could relate to this character and the laughing is lame acting way overdone (Jabberwacky-01459, October 2019).

Based on the statement above, it could be seen how the audience tries to fulfill the 'demand' by evaluating the movie, but it is not quite deep, which only gives surface evaluation. Clearly, the audience does not have adequate information regarding mental illness. It seems to be unfamiliar with the experience of psychological issues, which led the audience to draw an unfit conclusion about the main character's life. Moreover, the audience had a thought of why the main character should behave overreacting toward the incident of bullying received by him is indeed giving a crucial explanation of how the audience does not comprehend the seriousness of mistreatment from society toward an individual psychologically. Surely, it explains the fact that the barriers of the American community over a discussion of psychological issues are tremendous, which explains why Americans are unaware or insensitive toward this issue. In this case, the audience is merely producing the evaluation toward Joker (2019) by relying on personal thought of a general experience that causes them incapable of delivering constructive comment or review over the movie itself. Furthermore, the following statement is also showing almost 
similar feedback from the audience regarding the story, especially the main character's condition.

Joaquín Phoenix's unconvincing laughing, and looking like a beaten dog had brutally annoyed me after 5 minutes. The world is mean and bad, and you can only be bad and hit back. Chaos, anarchy, whatever .. inspires by a clown who killed 3 bullies. More of this stupid excess of brutality in the name of... what? Yes. It is the same director as in the hangover 3. I don't want to be a part of this. Brutal and boring. (Pedrovelazquezdiaz, 5 November 2019).

Based on the audience's statement above, it could be understood that how the audience apprehends the movie as an uninteresting story that merely contains too much emphasis on brutality features. The idea of this thought can possibly appear on the audience's mind is because they are still getting in a difficult time to actually figure out the essence of the movie itself, particularly the core value which was tried to be delivered by the director of the movie through the actions of the main character. The audience only can see the movie as a dull storyline because the audience is not putting their deep attention toward the whole idea of the story; they only see the main character's miserable life. In fact, the story is actually much more complex, which covers many relatable situations within the real context of American life. Thus, the portrayal of chaotic situations where there is chaos and anarchy going on in Gotham City as the setting of the movie is actually called a reflection of how several parts of the state in America also experiencing this kind of situation. Clearly, the earlier example where the audience delivered his opinion about the movie is showing how he evaluates the main character's behavior based on his experience living in society's life where it is full of mean and bad things which can only be encountered by doing the same thing. This is a form of 'imaginary' stage where the audience perceives and evaluates the main character by relying on his capability in reflecting his behavior and even the society over the main character's behavior. Furthermore, the phenomenon of how the audience seems to be missing the whole point of the movie still exists, like the following statement of the audience's opinion about Joker (2019).

Somehow the darkest and most serious movies get the highest ratings. People say that this movie is so thrilling and that Joaquin Phoenix deserves an Oscar, but at the end of the day, it wasn't entertainment. There were so many evil moments and dark scenes but what's so good about that? This movie was almost like instructions on how to be a psycho. They flipped the usual idea and boundaries of good and evil for the audience to feel sorry for the bad guy. People seem to think this is a good thing. It's bad! (Paullevantis, 19 October 2019)

The statement of the audience above could be inferred that how the audience reflecting the movie is quite far away from the great concept of Joker (2019), which actually conveyed or tried to reflect the glance of the real world where many Americans are struggling to face the harsh and difficult condition within the society. The emergence of people that unfortunately suffer psychological issues is something that they actually do not want to experience it as well within their life. Still, they are stuck in that kind of difficult situation where many people also rarely show positive support or treatment over their condition. In the case of Joker (2019) movie, for the audience who thought the movie is dark or nothing but giving bad influence toward the society, particularly promoting the idea of becoming cruel and psycho is showing that the 
audience reflecting the movie only what was displayed within the movie literally without having deeper comprehension regarded to how such a movie is created that way or why most of the people assume that the movie deserves to be awarded Oscar. Clearly, the audience is just intended to be part of the movie by constructing their own perspective based on their own reflection or interpretation to fulfill the "demand." Apparently, not all of the audience could participate coherently in giving the interpretation, since many of them produce misinterpretations over the movie as well by relying on their "reflection" between their personal context or life experience and the context of the movie.

\section{The Third Stage of Lacan's Psychoanalysis: The Symbolic}

Clearly, on the stage of symbolic based on Lacan's explanation is actually a phase where an individual starts to enter a language region or refers to social order, values, norms, and other structural aspects that are introduced to people. In addition, within this stage, an individual will be more exposed to logical thoughts and differentiation, which makes them have a desire to be proposed to reality. Within this stage, it explained the reason why the audience of Joker (2019) movie could produce an interpretation of misconception toward the phenomenon of mental illness, which is assumed to be associated with violence because they interpret the movie based on what they know and familiar within society. By perceiving the fact that the society is also aware of the existing public stigma over the mental illness, which indirectly makes the perception over individuals who suffer psychological issues commonly remain perceived negatively for a long time.
Thus, the misinterpretation produced by the audience actually conveys an unfulfilled or unachieved "desire" where they expect the emergence of Joker (2019) movie could clarify the irrelevant of public stigma toward mental illness in the American community. By examining the misperception over Joker (2019), the movie phenomenon is actually perceived as momentum for several audiences to raise awareness of having a friendly discussion toward the phenomenon of a psychological issue in America. Clearly, it could be seen through the following statement that the audience's misperception over Joker (2019) movie in interpreting the phenomenon of the psychological issue is implicitly containing the hopes or "desire" of people who are aware of this issue to elevate people's awareness of having better understanding toward a psychological issue that is happening in American society.

This is a movie that only those who have felt alone and isolated can truly relate to it. You understand the motive, and you feel sorry for the character. A lot of people will see this movie and think that it encourages violence. But truly, this movie should encourage each and every one of us to become a better person, treat everyone with respect and make each other feel like they belong in this world, instead of making them feel isolated (Lesterarnoldpinto, 7 October 2019).

Based on the statement, it could be seen how the audience's misperception is actually could be fixed by the chance of making them be more aware and courageous in order to understand as well as be more sensitive toward the situation of American society who mostly face psychological issues in diverse complexity. Thus, the movie itself is not only producing a variety of misinterpretations but also produces hopes or dreams of Americans 
concerning the enhancement toward the awareness of people in comprehending mental illness. The following statement will also confirm the idea of how actually the emergence of misinterpretation could be used as a chance to explain what is actually being delivered within the movie.

This movie causes the audience to consider many topics on morality, particularly the poor choices made by the Joker. The Joker is more relatable in this movie than antagonists usually are. I think this gives a more realistic view of "bad" people, who are not usually $100 \%$ bad in all ways as society often judges. It is important to know when to sympathize with the Joker (towards the beginning of the movie), and when he needs to be identified as a threat (when he begins making certain bad choices). This movie is only suitable for adults who are willing to pick it apart and think critically about it (Davestroud-76036, 4 October 2019).

Based on the statement above, the movie itself actually carries out positive messages where the creation of the main character can raise the discussion of morality. It makes the production of misinterpretation of Joker (2019) movie could be revised by raising awareness of mental illness issue and arousing the sense of morality among Americans community to be more practiced daily. Hopefully, the emergence of misperception toward mental illness and its public stigma could be changed properly through comprehending the creation of the Joker (2019) movie as the first attempt to start a positive action. Besides, the following statement of the audience's opinion about Joker (2019) movie is showing a perspective of how an individual perceives the movie as a story that has relevance regarding the existing social order or condition in reality.
The music. The intense. The realism. The performance. The story. Such a perfect combination of everything. I never felt that a character like Joker could be real until I saw this. Phoenix shows us what a joker is in our society and shows us how power can be obtained. Philips on the other hand had the perfect choice of music, camera angles, lighting and every important factor. Overall, I did not expect the story to be this perfect. Too many shocking turns happened and it really does represent today's society. If I was in the first screening, I would have applauded for $80 \mathrm{~min}$ not 8 (Ahakimshashaa, 3 October 2019).

By perceiving the way the audience delivers the opinion regarded to how the director could direct such an amazing and touching story is showing the audience's awareness toward social values and society's realm depicted within the story. The reason why the movie itself is called a representation of today's society is that the creation of Joker (2019) movie provides the audience a depiction of society's realm where it is full of manipulation of power and includes a portrayal of an individual who could obtain the power through a variety of alternatives and motives. Moreover, the success of the movie in carrying out the profound messages is through the performance of the main actor who could play his role beautifully. Henceforth, for the audience who can deliver an opinion about how relatable it is the movie with the society means that the audience could see underneath the performance of the main actors, which turns out to be a form of expression where an individual had to struggle for their life include struggling from society's pressure that causes distortion over their mental health. The following statement also shows how the creation of Joker (2019) as the main character of the movie could make the 
audience realize a huge fact that there is always a certain power that owns a tremendous influence within the society's realm, it is money.

The pool does not need the money. They need dignity and respect, coz that is what it takes to be a human. If you don't have that, money will only be a reminder of them being a "good boy." Like some politicians, they feel so frustrated when people from the lower class does not accept their funding champions. In this movie, through Joker's life, I begin to get it (Diorboeyoung, 4 October 2019).

Based on the statement above, it could be inferred that the performance of the main character within the movie is capable of arousing the audience's awareness regarding serious facts which always happened and remain practiced among society. In this respect, watching the movie and performing such evaluation by the audience is actually an attempt to be able to understand the movie as a whole; even there are several misinterpretations over the movie itself by the audience, but it still can be considered as an attempt as well. Basically, by considering the process of Lacan's psychoanalysis of the human's mind, particularly within the stage of 'symbolic' is concerning on how an individual performs his/her capability in comprehending and adjusting their condition with the social order and norms as well as in the case of the audience in evaluating Joker (2019) movie. Their evaluation is a form of comprehending the condition of the movie with the social order and norms within a real society's context. Thus, there are some insightful interpretations, and the others are interpretations that are full of judgment. Despite the occurrence of misinterpretation, the audience is basically showing their "desire" or "hope" regarding their society. In the following statement, there is an audience's perspective related to the movie and delivers crucial messages for the others as well.

This movie is so strong and Mr. Phoenix so impressive that I can nothing but pray to god and say thank you for the creation of those emotions I got watching this movie. It is the most brutal story about (lack of) love I have ever seen. Brutally human, political and mind blowing especially in regards to the deep connection you get to a person in our society that is in so deep need of just human warmth. The movie is a piece of art and I have rarely felt such emotions watching violent scenes. Must see and "must discuss" (Alexandermaximilian55256, 25 August 2020).

By analyzing the statement above, it can be understood that the audience is going through the stage of 'symbolic' where the audience could contextualize the existing phenomenon within the movie with the real context of society comprehensively. It could be seen as well through how the audience gave his highlight of giving more opportunities for every American society to have a wider and deeper discussion regarding social issues, including mental health. This is completely showing a form of 'hope' delivered through the movie's evaluation or interpretation.

\section{CONCLUSION}

Clearly, Joker (2019) movie affected the audience in constructing the misperception toward mental illness based on their personal interpretation of psychological issues portrayed within the main character's performance. Henceforth, applying the three stages of human development by Jacques Lacan, which are The Real, The Imaginary, and The Symbolic, could reveal the reasons how such misinterpretations over Joker (2019) 
movie is produced by American audiences. Considering their lack of awareness to be more open and humble in having wider discussion of mental health issues among the American community and the existence of negative public stigma regarding mental illness influences them to interpret the movie in such a way. Most importantly, the misinterpretation of Joker (2019) movie produced by the audience is implicitly raising hopes or American society's dreams to gain more attention in handling psychological or mental illness issues openly and seriously.

\section{REFERENCES}

Cawelti, John G. (1976). Adventure, mystery, and romance; formula stories as art and popular culture. The University of Chicago Press.

Driscoll, Annabel \& Husain, Mina. (2019). Why Joker's depiction of mental illness is dangerously misinformed. The Guardian. https://www.theguardian.com/film/2019 loct/21/joker-mental-illness-joaquinphoenix-dangerous-misinformed.

George, Mary W. (2008). The elements of library research. Princeton University Press,

Greenstein, Luna. (2017). The best movie about mental health. Mental Health. https://www.nami.org/Blogs/NAMIBlog/December-2017/The-Best-MoviesAbout-Mental-Health.

Lacan, J. (2014). The mirror stage as formative of the function of the $I$ as revealed in psychoanalytic experience (1949). Reading French Psychoanalysis, Routledge, 119-126.

Langley, Travis. (2019). The Joker psychology: Evil clowns and the women who love them. Sterling.

Parcesepe, Angela M., \& Cabassa, Leopoldo J. (2013). Public stigma of mental illness in the United States: A Systematic Literature Review. Adm policy ment health, 40(5).

Reynolds, Emily. (2020). How do films like 'Joker' shape attitudes towards people with mental health issues? Digest. https://digest.bps.org.uk/2020/05/06/ho w-do-films-like-joker-shape-attitudestowards-people-with-mental-healthissues/.

Severson, Ken. (2020). Is 'Joker' dangerous? The Joker movie controversy explained. Studiobinder.

https://www.studiobinder.com/blog/jok er-movie-controversy/.

Striedter, J. (2013). Literary Structure, Evolution, and Value. Harvard University Press.

https://doi.org/10.4159/harvard.978067 4418677.fm.

Wilkinson, Alissa. (2019). Joker is presumably laughing all the way to the bank after a record-breaking opening weekend. Vox. https://www.vox.com/culture/2019/10/7/ 20902694/joker-box-office-records. 